This document is the accepted manuscript version of the following article:

Defraeye, T., \& Verboven, P. (2017). Moisture barriers to control drying of fresh-cut fruit: quantifying their impact by modeling. Food and Bioproducts Processing, 101, 205-213. http://doi.org/10.1016/j.fbp.2016.10.016

This manuscript version is made available under the CC-BY-NC-ND 4.0

license http://creativecommons.org/licenses/by-nc-nd/4.0/

\title{
Moisture barriers to control drying of fresh-cut fruit: quantifying their impact by modelling
}

Thijs Defraeye ${ }^{a, b} *$, Pieter Verboven ${ }^{c}$

\author{
${ }^{a}$ Multiscale Studies in Building Physics, Empa, Überlandstrasse 129, 8600 Dübendorf, Switzerland \\ ${ }^{b}$ Chair of Building Physics, ETH Zurich, Stefano-Franscini-Platz 5, 8093 Zürich, Switzerland
}

${ }^{c}$ KU Leuven - University of Leuven, Division MeBioS, Postharvest Group, Willem de Croylaan 42, 3001 Heverlee, Belgium

* Corresponding author

- E-mail thijs.defraeye@empa.ch

- Tel. $\quad+41(0) 587654790$

- Fax. $\quad+41446331041$

Keywords: film, coating, hygrothermal, COMSOL, apple, convective

\section{Highlights}

- The drying kinetics of composite fruit-barrier systems are investigated by modelling

- The impact of barrier properties on the dehydration process is quantified

- A barrier induced a lower evaporation rate and a higher tissue temperature

- The coated fruit tissue leads to a more homogeneous water activity distribution inside the tissue.

\section{Abstract}

Moisture barriers are applied as functional interfaces between food products and their environment to control or limit the moisture exchange, a typical example being edible films. Hygrothermal continuum modelling is used to obtain insight on the impact of moisture barriers on the fruit dehydration process. The effects of moisture permeability and thickness of the barrier on the drying process are quantified, by looking into the drying kinetics and the internal moisture transport. Barriers are found to induce a smaller drying rate and a higher product temperature, but lead to more spatially-uniform drying within the sample. The sensitivity of the total drying time to the barrier's permeability is also found to be dependent on the permeability of the fruit tissue itself. The presence of a barrier significantly reduced the sensitivity of the drying time to an increase in air speed, thus convective transfer coefficients. Such hygrothermal simulations are a promising way to tailor moisture barriers to a specific application, in terms of optimal barrier permeability and thickness, to obtain the required drying characteristics. 


\section{Introduction}

In food processing, water vapor barriers are ubiquitously present. Their main function is to control or limit the water migration from food to the environment or from one food component to another. For fresh fruit, several types of barriers are present, each with their specific thickness and moisture permeability. The peel is the natural barrier protecting whole fruits from dehydration during long-term storage (Veraverbeke et al., 2003a). Dehydrating films are used to pack fresh-cut fruit prior to dehydration, and thereby induce better preservation of quality during lowtemperature drying (Laurienzo et al., 2010). Edible coatings or films (Dhall, 2013; Vargas et al., 2008) are used to cover minimally-processed fruit, such as ready-made fruit salad, but also dried fruit, bakery products, French fries, meat and chocolate products (Pavlath and Orts, 2009; Romanazzi et al., 2015), and aim to increase shelf life by controlling moisture loss. During solar assisted pervaporation, fruit juice, puree or slices are dehydrated inside a semi-permeable bag made out of a breathable textile, resulting in fruit leathers with extended shelf life, compared to fresh fruit (Phinney et al., 2015).

A lot of research has been performed on these different types of barriers for fruit, predominantly on the experimental side (Defraeye et al., 2016b). The main focus point is on engineering barriers with specific properties, such as a tailored moisture permeability. This is achieved for example by manufacturing methods which synthesize a specific porous microstructure or which produce a multilayer or composite barrier. The efficacy of these barriers can be evaluated directly, by determining the barrier's moisture transport properties (Silva et al., 2012; Thakhiew et al., 2011; Wong et al., 2014), or indirectly, by measuring their overall impact on product dehydration, for example via the weight loss of the fruit (Petriccione et al., 2015). Note that the presence of the barrier actually makes a composite material out of the fruit tissue-barrier ensemble.

We still lack detailed insight on how these barriers affect the fruit dehydration process, particularly with respect to the local drying kinetics and the transient moisture distribution inside the fruit. Such information is imperative for choosing and designing the right barrier for a certain application. For this purpose, numerical modelling provides a convenient alternative to experiments (Defraeye, 2014). Such modelling provides high spatial and temporal resolution on moisture transport predictions. Another particular advantage is that the properties (thickness, moisture permeability) of this very thin barrier can be exactly controlled. In experiments however, some biological and experimental variability will be inherently present, which makes extensive parametric studies challenging. Such hygrothermal continuum modelling has however been rarely used to look into the impact of moisture barriers for fruit dehydration (Veraverbeke et al., 2003a, 2003b). In this context, such modelling has not been used for forced, non-isothermal convective drying conditions.

This study targets new insights on the impact of various moisture barriers on fruit dehydration by relying on mechanistic modelling. To this end, a parametric study is performed for varying barrier thickness and moisture permeability, but also for different fruit tissue material. In addition, the influence of the environmental conditions on 
the dehydration of the composite material is also explored. This study provides a first step in using hygrothermal simulations towards tailoring moisture barriers to obtain specific drying characteristics. 


\section{Materials and methods}

\subsection{Continuum model for fruit tissue}

A continuum model was developed and validated previously (Defraeye and Verboven, 2016) to calculate the heat and moisture transfer in biological tissue, such as fruit or moisture barriers, during drying. Only its main characteristics are highlighted below and more details can be found elsewhere (Defraeye and Verboven, 2016). The main model assumptions are that evaporation is assumed to occur only at the air-barrier interface and that shrinking and swelling of the tissue and barrier are not modelled.

\section{Conservation equations}

The following conservation equations for moisture and energy are solved in the fruit tissue and in the moisture barrier for the dependent variables temperature $T[\mathrm{~K}]$ and water potential $\psi[\mathrm{Pa}]$ :

$$
\begin{aligned}
& \frac{\partial w_{m}}{\partial \psi} \frac{\partial \psi}{\partial t}+\nabla \cdot\left(-K_{m} \nabla \psi\right)=0 \\
& h_{l} \frac{\partial w_{m}}{\partial \psi} \frac{\partial \psi}{\partial t}+\left(c_{p, s} w_{s}+c_{p, l} w_{m}\right) \frac{\partial T}{\partial t}+\nabla \cdot\left(-h_{l} K_{m} \nabla \psi\right)+\nabla \cdot\left(-\lambda_{P M} \nabla T\right)=0
\end{aligned}
$$

where $w_{s}$ and $w_{m}$ are the dry matter density (solid) and moisture content of the tissue or barrier $\left[\mathrm{kg} \mathrm{m}^{-3}\right]$, respectively. $K_{m}$ is the moisture permeability of the tissue or barrier $[\mathrm{s}], h_{l}$ is the enthalpy of liquid water $\left[\mathrm{J} \mathrm{kg}^{-1}\right], \lambda_{P M}$ is the thermal conductivity of the tissue or barrier (porous medium) $\left[\mathrm{W} \mathrm{m}^{-1} \mathrm{~K}^{-1}\right], c_{p, s}$ and $c_{p, l}$ are the specific heat capacities of dry matter and liquid water $\left[\mathrm{J} \mathrm{kg}^{-1} \mathrm{~K}^{-1}\right]$, respectively. These material properties are given in Table 1. $K_{m}$ and the sorption isotherm for fruit tissue are taken from Aregawi et al. (2013a). The first term in Eq. (1) includes the moisture capacity $C_{m}=\frac{\partial w_{m}}{\partial \psi}$. Note that, for the present study, all material properties for the moisture barrier are taken equal to those of the fruit tissue, except for the moisture permeability. This implies that the barrier is a hygroscopic material. This assumption is justified as the main focus is on the barrier behavior, and as the barrier is thin.

In the energy conservation equation (Eq. (2)), the first and the third term on the left-hand side originate from a derivation of the general conservation equation to the dependent variables $T$ and $\psi$ (Defraeye et al., 2012b). The impact of the first and third term is actually very low for the present study due to the low drying rates. The difference of simulations with and without these terms could almost not be noticed in the drying curves. These terms are not accounted for in many studies. Note that moisture transport is not split up in vapor and liquid water transport, leading to only one conservation equation, as done in several other studies (Aregawi et al., 2013b; Esfahani et al., 2014; Tzempelikos et al., 2015). Evaporation is only assumed to occur at the surface, implying that moisture transport in the fruit tissue occurs via the liquid phase and not by water vapor. 


\section{Boundary conditions}

The boundary conditions at the air-barrier interface (continuity of fluxes) are specified as:

$\mathbf{n} \cdot\left(-\mathrm{K}_{\mathrm{m}} \nabla \psi\right)=\mathrm{g}_{\mathrm{m}}=\mathrm{h}_{\mathrm{c}, \mathrm{m}}\left(\mathrm{p}_{\mathrm{v}, \mathrm{w}}-\mathrm{p}_{\mathrm{v}, \mathrm{ref}}\right)$

$\mathbf{n} \cdot\left(-\mathrm{h}_{1} \mathrm{~K}_{\mathrm{m}} \nabla \psi-\lambda_{\mathrm{PM}} \nabla \mathrm{T}\right)=\mathrm{g}_{\mathrm{T}}=\left(\mathrm{h}_{\mathrm{c}, \mathrm{T}}\left(\mathrm{T}_{\mathrm{w}}-\mathrm{T}_{\mathrm{ref}}\right)-\mathrm{h}_{\mathrm{v}} \mathrm{g}_{\mathrm{m}}\right)$

where $g_{m}\left[\mathrm{~kg} \mathrm{~m}^{-2} \mathrm{~s}^{-1}\right]$ and $g_{T}\left[\mathrm{~J} \mathrm{~m}^{-2} \mathrm{~s}^{-1}\right]$ are the mass and heat fluxes at the interface, $\mathbf{n}$ is the unit vector normal to the interface, $h_{c, m}$ is the convective mass transfer coefficient (CMTC $\left.\left[\mathrm{s} \mathrm{m}^{-1}\right]\right), h_{c, T}$ is the convective heat transfer coefficient (CHTC $\left.\left[\mathrm{W} \mathrm{m}{ }^{-2} \mathrm{~K}^{-1}\right]\right), p_{v, w}$ and $p_{v, \text { ref }}$ are the vapor pressures at the interface and of the ambient air $[\mathrm{Pa}], T_{w}$ and $T_{\text {ref }}$ are the temperatures at the interface and of the ambient air [K], $h_{v}$ and $h_{l}$ are the enthalpies of water vapor and liquid water $\left[\mathrm{kg}^{-1}\right]$.

For mass transfer, the boundary condition states that moisture loss from the composite material (tissue + barrier) equals the convective vapor removal at the air-barrier interface. For heat transfer, the boundary condition states that heat loss from the composite material, due to conduction and liquid water transport, equals the convective (sensible) heat exchange with the environment and the heat removal due to the water vapor loss, including evaporation. In the present study, long-wave radiation exchange of the composite material with the environment via the surface is not modelled.

Table 1. Material properties, boundary conditions and initial conditions for the base case.

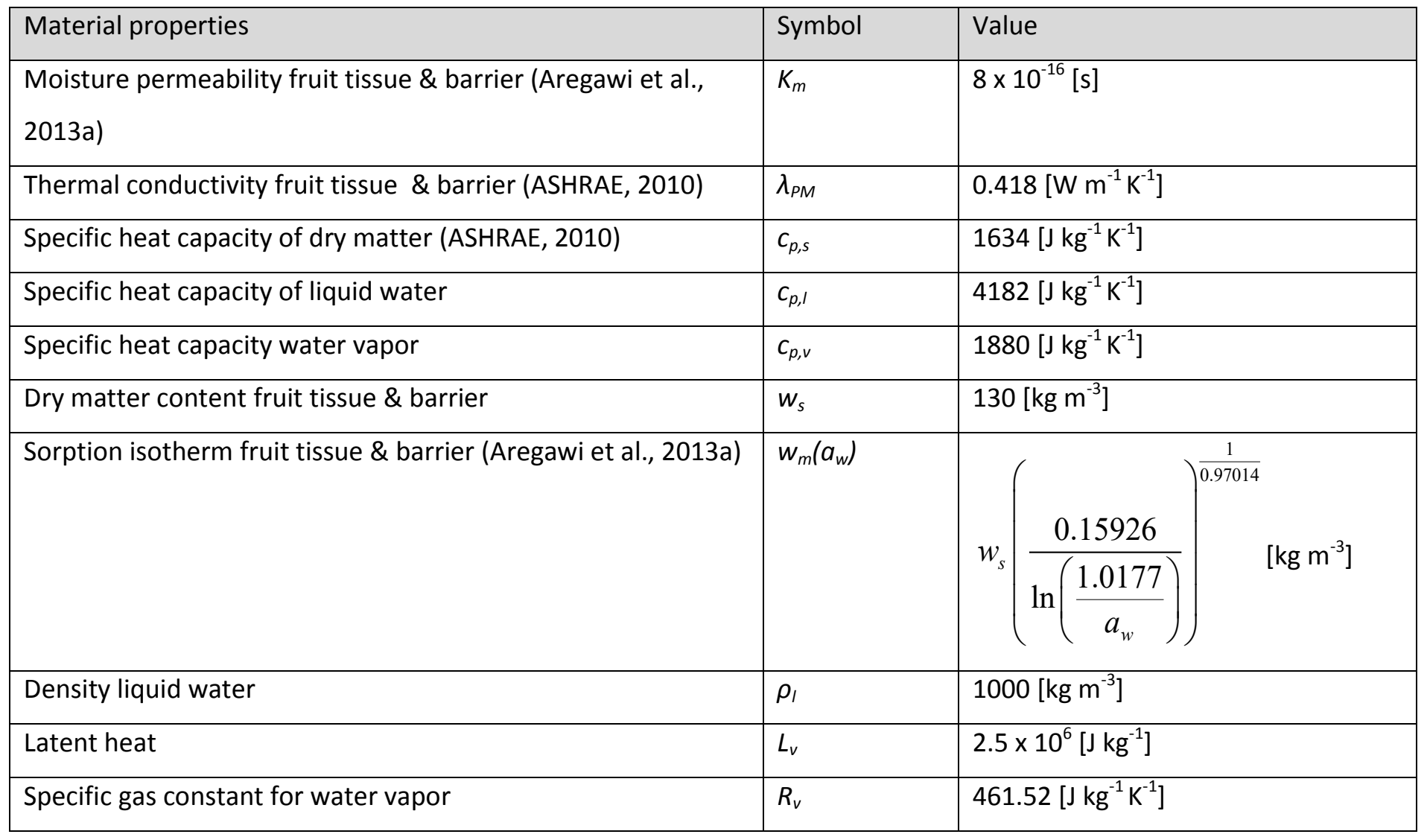




\begin{tabular}{|l|l|l|}
\hline Boundary and initial conditions & Symbol & Value \\
\hline Initial tissue temperature & $T_{\text {ini }}$ & $20\left[{ }^{\circ} \mathrm{C}\right]$ \\
\hline Initial tissue moisture content (dry base) & $X_{\text {ini }}$ & $6\left[\mathrm{~kg} \mathrm{~kg}^{-1}\right]$ \\
\hline Initial tissue moisture content & $W_{m, i n i}$ & $780\left[\mathrm{~kg} \mathrm{~m}^{-3}\right]$ \\
\hline Drying air temperature & $T_{\text {ref }}$ & $20^{\circ} \mathrm{C}$ \\
\hline Drying relative humidity & $R H_{r e f}$ & $30 \%$ \\
\hline Convective heat transfer coefficient & $h_{c, T}$ & $10\left[\mathrm{~W} \mathrm{~m}^{-2} \mathrm{~K}^{-1}\right]$ \\
\hline Convective mass transfer coefficient & $h_{c, m}$ & $7.03 \times 10^{-8}\left[\mathrm{~s} \mathrm{~m}^{-1}\right]$ \\
\hline
\end{tabular}

\section{Constitutive equations}

The enthalpies of liquid water and water vapor, $h_{l}$ and $h_{v}\left[\mathrm{Jg}^{-1}\right]$, are:

$\mathrm{h}_{1}=\mathrm{c}_{\mathrm{p}, 1}\left(\mathrm{~T}-\mathrm{T}_{\mathrm{ref}, 0}\right)$

$\mathrm{h}_{\mathrm{v}}=\mathrm{c}_{\mathrm{p}, \mathrm{v}}\left(\mathrm{T}-\mathrm{T}_{\mathrm{ref}, 0}\right)+\mathrm{L}_{\mathrm{v}}$

where $L_{v}$ is the heat of vaporization $\left[\mathrm{J} \mathrm{kg}^{-1}\right]$, also called latent heat, which is the energy needed for the phase change from liquid to vapor. $T_{\text {ref, },}$ is a reference temperature, taken equal to $273.15 \mathrm{~K}\left(0^{\circ} \mathrm{C}\right)$. To determine the moisture capacity $C_{m}=\frac{\partial w_{m}}{\partial \psi}$, the sorption isotherm ( $w_{m}$ vs. water activity $\left.a_{w}\right)$ is required for the fruit tissue and moisture barrier (see Table 1), as well as the relation of water activity $a_{w}$ to water potential $\psi$. The latter is given by:

$\psi=\rho_{l} R_{v} T \ln \left(a_{w}\right)$

The vapor pressures $p_{v, w}$ and $p_{v, \text { ref }}$ are determined based on the water activity at the interface $\left(a_{w, w}\right)$ and the relative humidity of the drying air $\left(R H_{r e f}\right)$, together with the corresponding temperatures, via the saturated vapor pressure $\left(p_{v, \text { sat }}[\mathrm{Pa}]\right)$ :

$p_{v, \mathrm{w}}=a_{w, \mathrm{w}} p_{v, \mathrm{sat}}\left(T_{w}\right)$

$p_{v, \text { ref }}=R H_{r e f} p_{v, \text { sat }}\left(T_{r e f}\right)$

$p_{v, \text { sat }}(T)=e^{65.8094-\frac{7066.27}{T}-5.976 \ln T}$

\subsection{Configuration and computational model}

The configuration used to evaluate convective drying of fresh-cut apple tissue is a cubic piece (length $L_{c}=20 \mathrm{~mm}$ ), covered with a moisture barrier (thickness $d_{b}[\mathrm{~m}]$ ), suspended in the surrounding air. This condition is representative 
for actual convective drying, as in that case, fruit pieces are placed on a tray with a wire mesh for example, so drying can also occur via all sides. This study uses apple fruit, as it is a frequently applied material to study fruit drying. A base case is simulated, as well as other variants. These variants evaluate, amongst others, different barrier permeabilities and thicknesses.

\section{Base case}

The computational model and the imposed boundary conditions are specified in Figure 1. A 3D model of the fruit cube is used, but only one eighth of the cube needed to be modelled due to symmetry. The tissue material is apple fruit (cv. Braeburn). The relevant material properties, boundary and initial conditions that are used for modelling are specified in Table 1. The fruit is assumed to be initially (fresh-cut state) at a uniform moisture content ( $\left.w_{m, i n i}\right)$ of 780 $\mathrm{kg} \mathrm{m}^{-3}$ at a uniform temperature $\left(T_{\text {ini }}\right)$ of $20^{\circ} \mathrm{C}$. This moisture content leads to a dry matter moisture content of $6\left(X_{i n i}\right.$ $\left.=w_{m, i n i} / w_{s}\left[\mathrm{~kg} \mathrm{~kg}^{-1}\right]\right)$. The fruit tissue is covered with a moisture barrier at the same conditions. For the base case, this barrier is given the same permeability as the fruit tissue $\left(K_{m, b}=K_{m, t}\right)$, and a thickness $\left(d_{b}\right)$ of $100 \mu \mathrm{m}$.
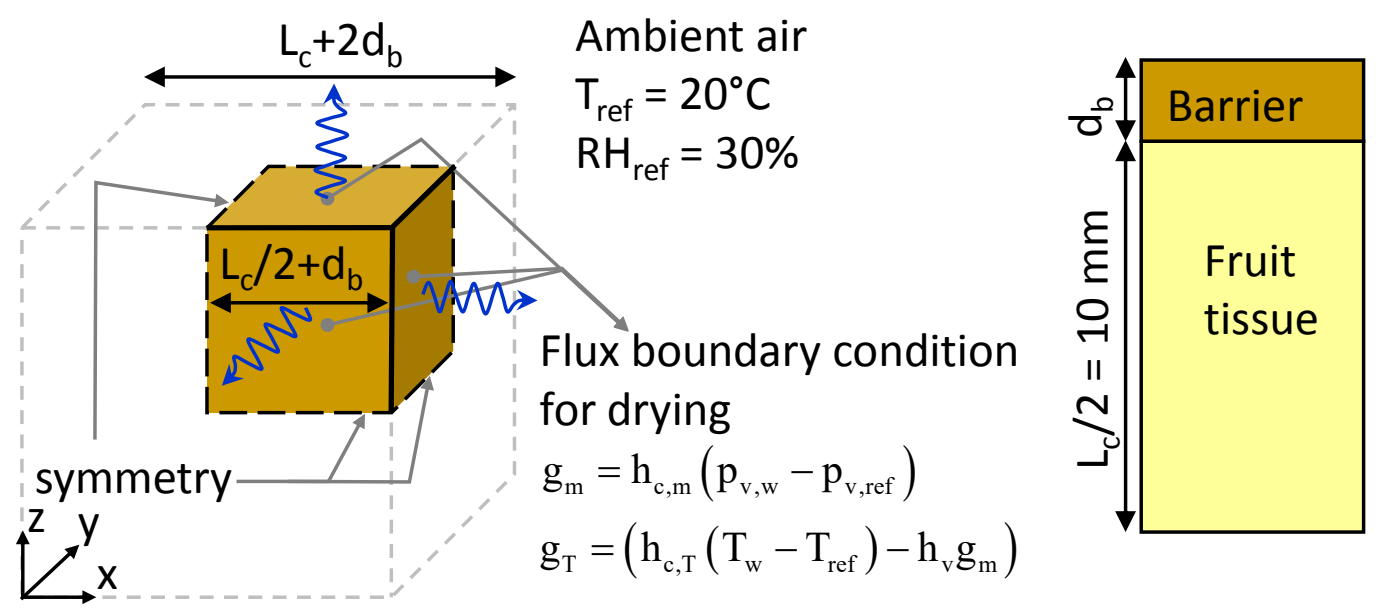

Figure 1. Computational model with boundary conditions.

The airflow around the composite cube is not explicitly modelled. The impact of the airflow on the drying process is accounted for indirectly in the model, namely by the use of convective transfer coefficients (CTCS). The same value for the CTCs is assumed on all sides of the cube. This is a simplified representation as usually a spatial CTC variation between the sides of the cube exists for forced convection, depending on the flow direction (Ateeque et al., 2014; Kaya et al., 2006). Within the scope of this study, including such a spatial variation is not relevant. The ambient air is kept at a constant temperature $\left(T_{\text {ref }}\right)$ and relative humidity $\left(R H_{\text {ref }}\right)$. The convective heat transfer coefficient was $10 \mathrm{~W}$ $\mathrm{m}^{-2} \mathrm{~K}^{-1}$ for the base case, implying rather low convection rates. The CMTC is estimated from the CHTC using the heat and mass transfer analogy, similar as reported in literature (Defraeye et al., 2012b), leading to a ratio CMTC/CHTC (analogy factor) of $7.03 \times 10^{-9}$.

An appropriate grid is built for the composite material, based on a grid sensitivity analysis. The grid consists of 91125 hexahedral finite elements, namely 45 divisions on each side of the cube $\left(1 / 8^{\text {th }}\right)$, of which 5 for the barrier. A gradual 
refinement towards the tissue-barrier interface is applied to enhance numerical accuracy and stability as the largest gradients occur there, especially at the start of the drying process. 


\section{Variants}

Different types of variants are simulated (Table 2). A first type considers different barrier properties, so various combinations of barrier thickness and permeability. A second type considers drying of a fruit material with a 10 times higher tissue permeability. The main reason for evaluating such a higher permeability is to account for the fact that often a large variation in measured tissue permeability is found for a single fruit species (Defraeye and Verboven, 2016). The cause for these variations are differences between cultivars and harvest years, amongst others. A third type targets other drying conditions, namely higher air speeds, so CHTC (convective heat transfer coefficient) and CMTC (convective mass transfer coefficient), for two different barrier permeabilities, in addition to the permeability of the base case. The higher CTCs are obtained by multiplying each time with a factor $10^{0.5}$, which is chosen to obtain a realistic range of CTCS which lie also not too far apart. Table 2. Drying conditions for different variants. If no value is specified (indicated by a dash), the same one is taken as the base case.

\begin{tabular}{|c|c|c|c|c|}
\hline Variant name & $\begin{array}{l}\text { Permeability tissue } \\
K_{m, t}[\mathrm{~s}]\end{array}$ & $\begin{array}{l}\text { Permeability barrier } \\
K_{m, b}[s]\end{array}$ & Thickness barrier $d_{b}[\mu \mathrm{m}]$ & $\begin{array}{l}\text { CHTC } \\
{\left[\mathrm{W} \mathrm{m}^{-2} \mathrm{~K}\right.} \\
\left.{ }^{1}\right]\end{array}$ \\
\hline Base case & $8 \times 10^{-16}$ & $8 \times 10^{-16}$ & 100 & 10 \\
\hline \multicolumn{5}{|l|}{ Type 1: Barrier properties } \\
\hline Kmb_8e-17 & - & $8 \times 10^{-17}$ & - & - \\
\hline Kmb_8e-18 & - & $8 \times 10^{-18}$ & - & - \\
\hline Kmb_8e-19 & - & $8 \times 10^{-19}$ & - & - \\
\hline Kmb_8e-18_db_10um & - & $8 \times 10^{-18}$ & 10 & - \\
\hline Kmb_8e-18_db_1000um & - & $8 \times 10^{-18}$ & 1000 & - \\
\hline \multicolumn{5}{|l|}{ Type 2: Fruit material } \\
\hline Kmt_8e-15_Kmb_8e-15 & $8 \times 10^{-15}$ & $8 \times 10^{-15}$ & - & - \\
\hline Kmt_8e-15_Kmb_8e-16 & $8 \times 10^{-15}$ & $8 \times 10^{-16}$ & - & - \\
\hline Kmt_8e-15_Kmb_8e-17 & $8 \times 10^{-15}$ & $8 \times 10^{-17}$ & - & - \\
\hline Kmt_8e-15_Kmb_8e-18 & $8 \times 10^{-15}$ & $8 \times 10^{-18}$ & - & \\
\hline \multicolumn{5}{|l|}{ Type 3: Drying conditions } \\
\hline Kmb_8e-16_CHTC31 & - & - & - & 31.6 \\
\hline Kmb_8e-16_CHTC100 & - & - & - & 100 \\
\hline Kmb_8e-16_CHTC316 & - & - & - & 316 \\
\hline Kmb_8e-17_CHTC31 & - & $8 \times 10^{-17}$ & - & 31.6 \\
\hline Kmb_8e-17_CHTC100 & - & $8 \times 10^{-17}$ & - & 100 \\
\hline
\end{tabular}




\begin{tabular}{|l|l|l|l|l|}
\hline Kmb_8e-17_CHTC316 & - & $8 \times 10^{-17}$ & - & 316 \\
\hline Kmb_8e-18_CHTC31 & - & & & \\
\hline Kmb_8e-18_CHTC100 & - & $8 \times 10^{-18}$ & - & 31.6 \\
\hline Kmb_8e-18_CHTC316 & - & $8 \times 10^{-18}$ & - & 100 \\
\hline
\end{tabular}

\subsection{Numerical simulations}

This hygrothermal continuum model was implemented in COMSOL Multiphysics (version 5.2), which is a finiteelement based solver. The partial differential equations interface (coefficient form) was used, in which the aforementioned conservation equations were implemented. Transient simulations simulated a drying process of 100 hours, starting from the specified initial conditions. Such a long simulation time is needed as drying is performed at low temperatures and rather low convection rates. Typical forced convective drying times for apple slices range from less than a day to a few days, depending on the operating conditions and fruit size, amongst others. All simulations applied adaptive time stepping, as determined from a temporal sensitivity analysis. The tolerances for convergence and other solver settings were determined based on a sensitivity analysis as well. A fully coupled solver was used to solve to the dependent variables $\psi$ and $T$.

\section{Results}

\subsection{Impact of barrier properties}

The drying process for the base case and for three barriers with a different permeability (Table 2) from the simulations are compared in Figure 2. The mass loss (change of dry matter moisture content, $X=w_{m} / w_{s}$ ) of the fruit tissue (without barrier) and the drying rate to the environment are shown versus time, as well as the surfaceaveraged temperature and water activity (or relative humidity) at the air-barrier interface. The surface-averaged water activity below the barrier, so at the tissue-barrier interface is also indicated by dotted lines. The drying rate equals the surface-averaged mass flux at the air-barrier surface. The volume-averaged fruit temperature and the temperature below the film are very similar to the reported surface temperature, which is why they are not shown. The base case is indicated with a bold black line.

The critical moisture content $\left(w_{\text {crit }}\right)$ is also shown in Figure 2a. The latter is defined in this study as the (volumelaveraged moisture content in the fruit tissue that corresponds, via the sorption isotherm, to an equilibrium water activity below which no spoilage occurs $\left(a_{w, c r i t}\right)$. For dried fruit, this $a_{w, c r i t}$ is about 0.6 (Bonazzi and Dumoulin, 2011). If the drying process is stopped once the (volume-)averaged moisture content reaches $w_{\text {crit }}$, and if the sample is then equilibrated at $a_{w, c r i t}$ or a lower water activity, the average final water activity in the tissue will be below $a_{w, c r i t}$. Note that this critical moisture content does not equal the which is often used in drying studies. This equilibrium value is 
the moisture content at which no further moisture loss (or uptake) occurs with time. For the present study, $w_{\text {crit }}$ was $37.8 \mathrm{~kg} \mathrm{~m}^{-3}$, leading to an $X_{\text {crit }}$ of $0.29 \mathrm{~kg} \mathrm{~kg}^{-1}$. Once the sample reaches $w_{\text {crit }}$, it can be considered to be sufficiently dehydrated with respect to spoilage. Hence $w_{\text {crit }}$ is a good criterion to mark the end of a drying process.

Furthermore, the conditions during the constant drying rate period (CDRP) are estimated analytically and are depicted in Figure 2. The CDRP is normally found during the first stages of the drying process and is characterized by a high relative humidity $(\mathrm{RH})$ at the surface $(\approx 100 \%)$, an almost constant drying rate and a constant material temperature, which is close to the wet bulb temperature $\left(T_{w b}\right)$. During the CDRP, the convective heat supply to the interface is quasi entirely used for the evaporation of water. Here it is assumed that no radiative heat flows at the surface are present as well as no (conductive) heat flows from the interior of the porous material. The CDRP predictions for drying rate and mass loss (Defraeye and Verboven, 2016$)$ assume a moist surface $(\mathrm{RH} \approx 100 \%)$ which is at the wet bulb temperature. The wet bulb temperature can be determined from psychrometrics. 

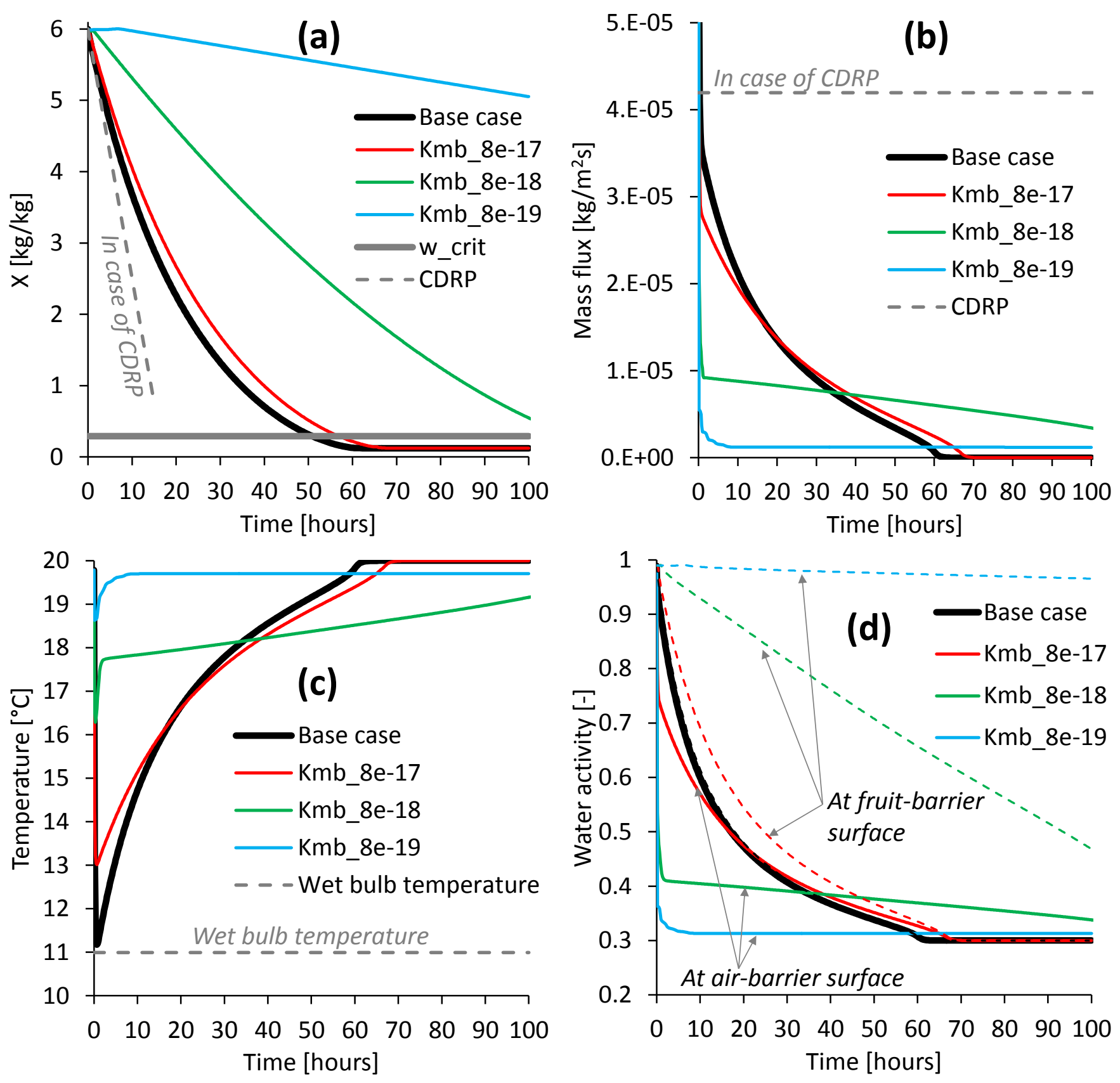

Figure 2. Comparison of drying process simulations of the base case and three different barrier permeabilities: Dry matter moisture content, including the critical moisture content $w_{m, \text { crit }}(a)$, drying rate $(b)$, temperature at the surface of the barrier with the air (c) and corresponding water activity at the surface of the barrier (full lines) and below the barrier surface (dotted lines) (d), as a function of time. CDRP indicates the conditions during the constant drying rate period.

The presence of each of the three barriers clearly lowers the drying rate. As expected, this rate decreases with lower barrier permeability. No CDRP is found during tissue dehydration without a barrier (base case), which is typical for a lot of fresh-cut fruits, including apples (Ateeque et al., 2014; Ben Mabrouk et al., 2012; Mcminn and Magee, 1999). With a barrier, an additional resistance to mass transfer from the fruit surface to the environment is imposed, where the water activity difference at both sides of the barrier clearly increases with decreasing permeability. 
Although this resistance decreases the drying rate significantly, it induces similar conditions to the CDRP for a very low barrier permeability (Kmb_8e-19), namely quasi constant quantities like moisture flux, temperature and water activity at the fruit surface. The reason is that the barrier slows down the drying process to such an extent that the transport of moisture from the interior to the fruit surface is not dominating the moisture removal anymore. Instead moisture transport from the fruit surface to the environment is dominating the moisture transport kinetics, as it needs to pass through the less permeable barrier. As a result, the water activity below the barrier is very high, as water transport to the fruit tissue interface through the tissue is sufficiently fast, compared to the moisture removal from that interface through the barrier.

As such, with a pronounced barrier, the fruit remains rather moist at its surface during dehydration. This can be beneficial for fruit quality due to the reduced moisture gradients near the surface and the associated hygric stresses and shrinkage, which are precursors for surface cracking and case hardening. This apparent CDRP comes however at the cost of a significant slowing down of the drying process, by which the fruit becomes more susceptible for microbial degradation processes. The reduced evaporation rate also brings the fruit temperature closer to that of the ambient air, so much higher than the wet bulb temperature. Thereby, the tissue near the surface is exposed to higher temperatures compared to uncoated fruit, which could damage heat-sensitive compounds in the fruit.

Next to the permeability, the impact of the barrier thickness is compared in Figure 3, namely for $10 \mu \mathrm{m}, 100 \mu \mathrm{m}$ and $1000 \mu \mathrm{m}$ barriers with a permeability of $K_{m, b}=8 \times 10^{-18} \mathrm{~s}$. A similar effect as with changing the permeability is observed, namely an increasing barrier thickness, so moisture resistance, decreases the drying rate. Previous results with different permeabilities are also shown (Kmb_8e-17 and Kmb_8e-19) for a barrier thickness of $100 \mu \mathrm{m}$. The reason for this is that their 1D moisture resistance $\left(R_{m, b}=d_{b} / K_{m, b}\right)$ equals that of Kmb_8e-18_db_10um and Kmb_8e18_db_1000um, respectively. This resistance is defined based on the flux through the barrier and the water potential difference over the barrier $\left(\Delta \psi_{b}\right)$ :

$\mathrm{g}_{\mathrm{m}}=-\mathrm{K}_{\mathrm{m}, \mathrm{b}} \nabla \psi_{\mathrm{b}} \approx-\mathrm{K}_{\mathrm{m}, \mathrm{b}} \frac{\Delta \psi_{\mathrm{b}}}{\mathrm{d}_{\mathrm{b}}}=-\frac{\Delta \psi_{\mathrm{b}}}{\mathrm{R}_{\mathrm{m}, \mathrm{b}}}$

For thin barrier layers (Kmb_8e-18_db_10um vs. Kmb_8e-17), it seems a linear scaling can be done with permeability and thickness: to reduce a certain barrier resistance, the thickness can be reduced for a certain barrier material, or its permeability can be increased with the same factor, while keeping the thickness constant. For larger barrier thicknesses, 3D effects play a role, as indicated by the difference between Kmb_8e-18_db_1000um and Kmb_8e-19. Note that the different drying behavior of Kmb_8e-18_db_1000um is attributed to the fact that the volume of the barrier is quite large, as the barrier is quite thick. As such, the composite nature of the material is clearly reflected in the drying curve. 


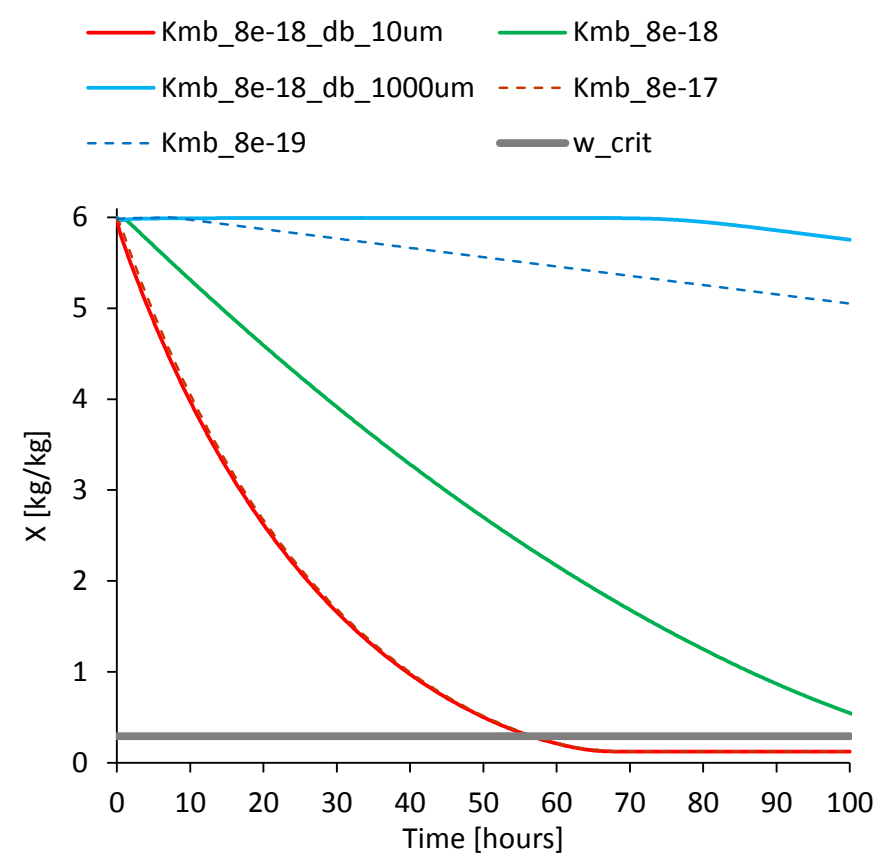

Figure 3. Comparison of drying process simulations for three different barrier thicknesses: Dry matter moisture content, including the critical moisture content $w_{m, \text { crit }}$ as a function of time. The dotted lines indicate simulation results for a barrier thickness of $100 \mu \mathrm{m}$ with two different permeabilities.

To obtain insight on the drying behavior inside the fruit tissue, the dry matter moisture content and the water activity in the sample at different points in time are shown in Figure 4 and 5 for the base case and the case with a 100 times lower barrier permeability (Kmb_8e-18). A cross section through the center of the cube is presented, so in the symmetry plane. It should be kept in mind that in reality, some shrinkage of the sample will occur. Shrinkage will predominantly occur in the dry tissue regions (blue zones in Figure 4), since for a large part of the drying process, the volume change is linearly proportional to the change in water content of the tissue (Mayor and Sereno, 2004). As shrinkage was not modelled in the present study, the dry layer in these figures appears somewhat thicker than in reality.

For the base case, the moisture content gradients near the drying front inside the fruit are very high, so concentrated within a small zone. Apart from the dry layer, the (wet) tissue has a quite uniform moisture content distribution, with a high moisture content. This behavior has been observed in experiments as well (Aregawi et al., 2013a; Defraeye et al., 2016a, 2012a). From recent simulations (Defraeye and Verboven, 2016), also higher gradients are found at lower tissue permeabilities. The gradients in water activity are less pronounced than those in moisture content, which is related to the highly nonlinear sorption isotherm where even moderate water activities corresponds to very low moisture contents. For the case with a moisture barrier however, the water activity (thus water potential) gradients occur predominantly over the barrier. Nevertheless, a rather dry zone exists within the tissue, but this zone still has a clearly higher moisture content than when no barrier is present. 
A particular advantage of the simulations is that the process parameters within the fruit tissue and at its interface (moisture flux, temperature and water activity) can be identified at these exact spatial locations of interest.

Obtaining their distribution within the tissue or surface/volume-averaged quantities at the same spatial and temporal resolution is much more challenging in experiments.

\section{No barrier (Base)}
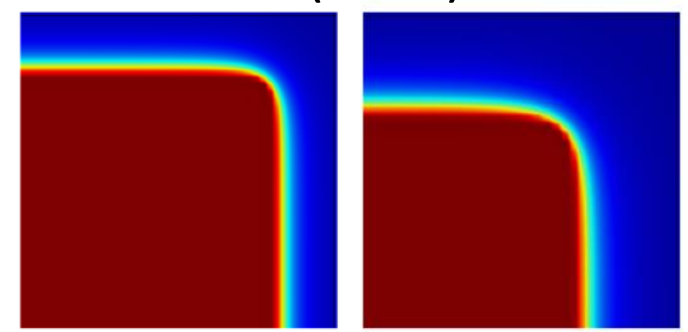

\section{Barrier (Kmb_8e-18)}

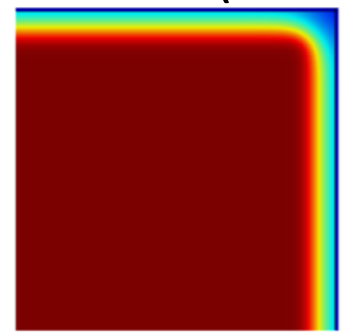

10 hours

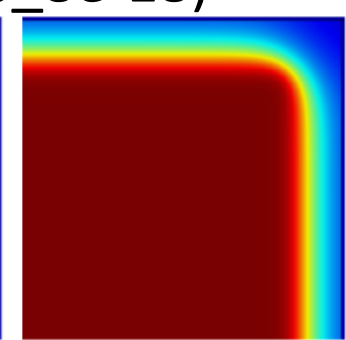

20 hours

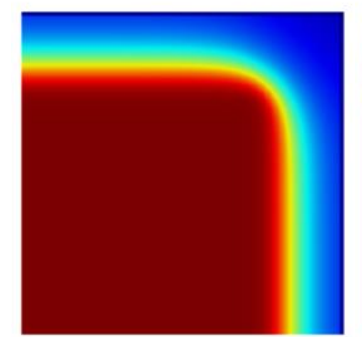

30 hours

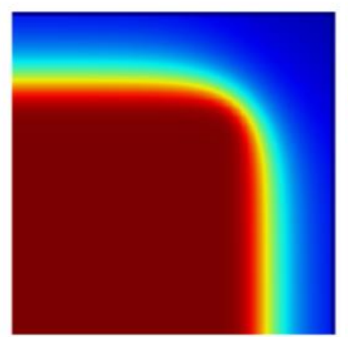

40 hours

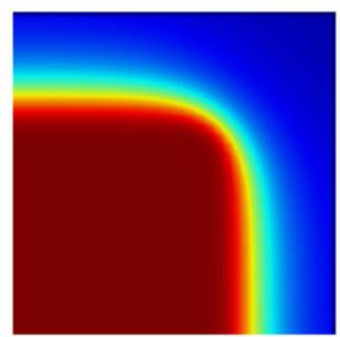

50 hours

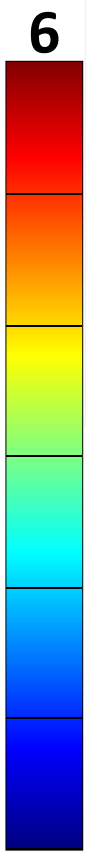

0

Figure 4. Dry matter moisture content $(X)$ in a center plane of the cube (1/4 of cube depicted due to symmetry) at different points in time for the base case and a case with a barrier with a permeability 100 times lower than fruit tissue. 
No barrier (Base)
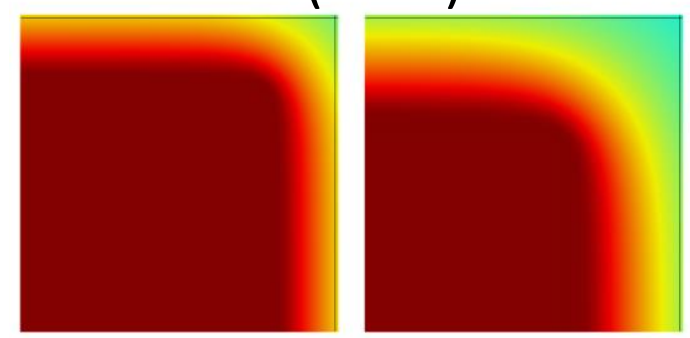

Barrier (Kmb_8e-18)

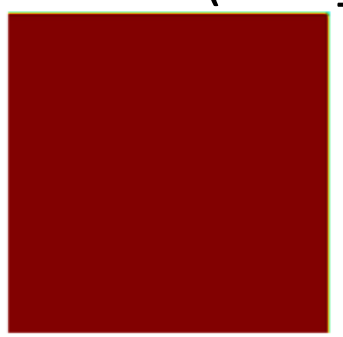

10 hours

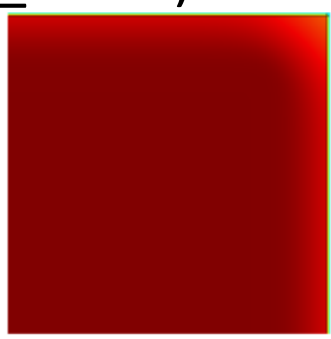

20 hours

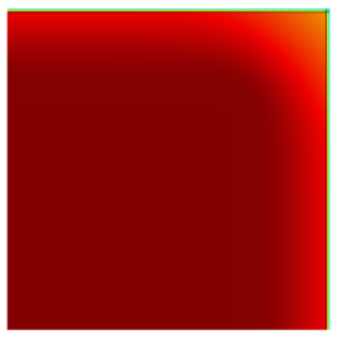

30 hours

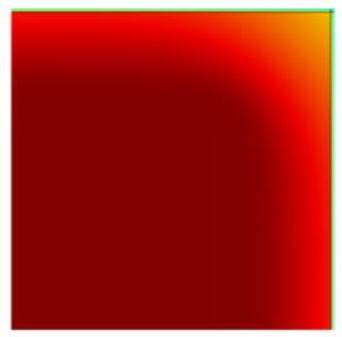

40 hours
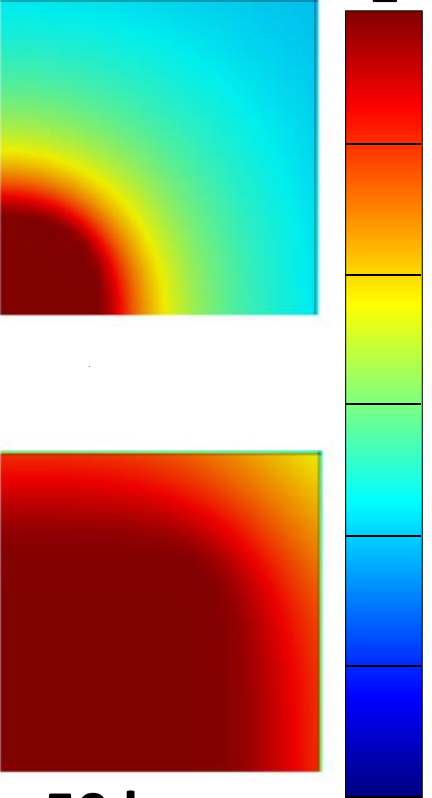

50 hours

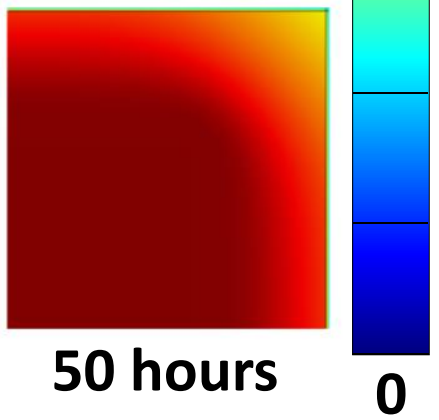

Figure 5. Water activity $a_{w}$ (range $\left.0-1\right)$ in a center plane of the cube (1/4 of cube depicted due to symmetry) at different points in time for the base case and a case with a barrier with a permeability 100 times lower than fruit tissue. 


\subsection{Different fruit tissue}

The impact of moisture barriers on the dehydration of fruit is evaluated for a fruit tissue with a 10 times higher permeability than the base case. Since comparing drying processes based on drying curves (e.g. Figure 2) is not that straightforward in a quantitative way, an alternative way of evaluating the results is chosen. To this end, the critical drying time $\left(t_{c r i t}\right)$ is introduced. It is the time needed for the sample to reach the critical moisture content $\left(w_{c r i t}\right)$, which was defined in section 3.1. $w_{\text {crit }}$ is a good criterion to mark the end of a drying process, since at that point the sample can be considered sufficiently dehydrated to avoid spoilage. With $t_{\text {crit, }}$ only one characteristic value is obtained per drying curve, which facilitates quantifying differences between drying processes. For both fruit tissue permeabilities, the critical drying time is determined for multiple barriers (Table 2). These critical times are depicted in Figure 6, scaled with that of the case when $K_{m, b}=K_{m, t}$ for each tissue permeability. For these cases (i.e. base case and Kmt_8e-15_Kmb_8e-15), $t_{\text {crit }}$ equals $51 \mathrm{~h}$ and $22 \mathrm{~h}$, respectively. This scaled time is shown as a function of the permeability ratio, namely $K_{m, t} / K_{m, b}$. Note that for some simulations, a longer drying time than 100 hours needed to be simulated.

The results clearly show that the permeability of the tissue has a large effect on how the drying time increases with decreasing barrier permeability. For rather permeable tissues $\left(K_{m, t}=8 \times 10^{-15}\right)$, reducing the barrier's permeability leads to a rather limited (relative) increase in the drying time, in comparison to a more impermeable tissue. The relative sensitivity of the drying time to the barrier's permeability is thus the largest for more impermeable tissues. Barrier efficacy is thus strongly connected with the tissue properties, which has to be acknowledged while assessing barrier performance.

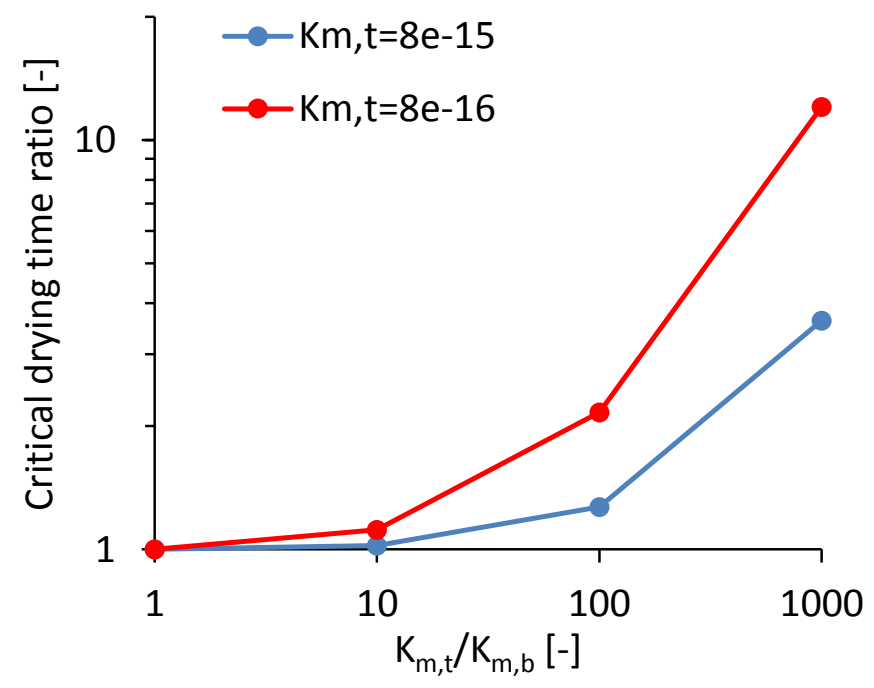

Figure 6. Critical drying time (scaled with $t_{c r i t}$ for the case when $K_{m, b}=K_{m, b}$ logarithmic scale) as a function of the permeability ratio $\left(K_{m, t} / K_{m, b}\right.$ logarithmic scale) for two different fruit tissue permeabilities. 


\subsection{Impact of drying conditions}

The considered barriers form significant resistances for moisture transport. For forced convection, the resistance of the boundary layer to mass transfer is much smaller compared to that of the barrier, but also of the fruit tissue. As such, the sensitivity of the drying process to the CMTC, thus airflow rate, is rather limited (Defraeye and Verboven, 2016). The thin barrier layers however do not form a pronounced barrier for heat transport. As such, increasing the air speed, thus CHTC, can still affect the drying rate as the supply of heat to the fruit is also essential for the evaporation of water, next to its convective vapor removal. The impact of an increase in CTCs (both CHTC and CMTC) on fruit tissue dehydration is demonstrated in Figure 7. To this end, the (scaled) critical time is shown as a function of the CHTC for tissue without a barrier and for two barrier types. Note that changing the CHTC implies also that the $\mathrm{CMTC}$ is altered, as both are linked (section 2.1). Here, each $t_{\text {crit }}$ is scaled with the $t_{\text {crit }}$ corresponding to $\mathrm{CHTC}=10 \mathrm{~W}$ $\mathrm{m}^{-2} \mathrm{~K}^{-1}$ for each case, which is $51 \mathrm{~h}$ (base), $57 \mathrm{~h}\left(\mathrm{Kmb} \_8 \mathrm{e}-17\right)$ and $110 \mathrm{~h}\left(\mathrm{Kmb} \_8 \mathrm{e}-18\right)$.

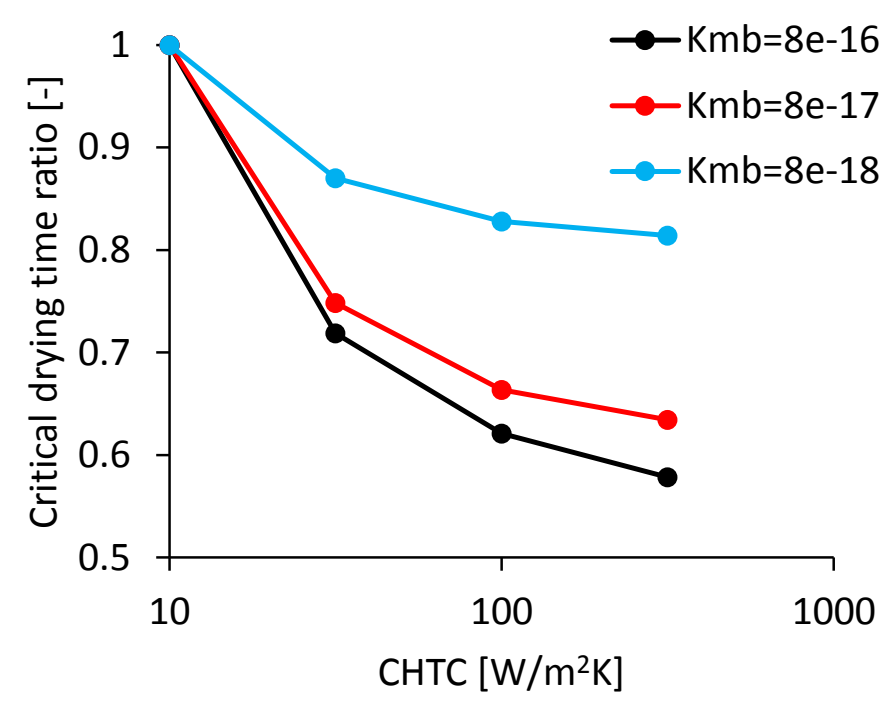

Figure 7. Critical drying time (scaled with $t_{\text {crit }}$ for the case where CHTC $=10 \mathrm{~W} \mathrm{~m}^{-2} \mathrm{~K}^{1}$ ) as a function of the CHTC (logarithmic scale) for three different barrier permeabilities.

Higher CTCs clearly reduce the drying time. The critical drying time however becomes less sensitive to a change in CTCs for higher CTC values for all three cases. The reason is that at higher speeds, the resistance of the boundary layer to heat (and mass) transfer is reduced, compared to that of the tissue (and barrier), to such an extent that the transport in the tissue-barrier composite will dominate the drying kinetics. For mass transfer, this effect occurs earlier than for heat transfer (Defraeye and Verboven, 2016). When a barrier is present, the sensitivity to the CTCS reduces more compared to without a barrier, due to the larger total resistance to mass transfer of the composite material.

Nevertheless, it is clear that even when a barrier is present, a significant reduction in drying time can be achieved by increasing the air speed, and thereby altering the CTCs: for a $100 \mu \mathrm{m}$ thick barrier with a permeability 100 times 
larger than the fruit tissue, so quite impermeable, increasing the CTCs with a factor 10 led to a $17 \%$ decrease of the drying time. Without a barrier, a decrease of the drying time of $38 \%$ was obtained.

This effect is relevant when using films or coatings to preserve certain properties (e.g. volatile compounds) during drying (Laurienzo et al., 2010), which have as a side effect that they strongly restrict moisture removal. By increasing the airflow rate, the drying process can be accelerated to increase throughput of products in the dryer and to avoid moisture-related degradation reactions. Particularly at higher temperatures, this acceleration will be more attributed to an enhanced convective heat supply to the surface, rather than convective vapor removal (Defraeye and Verboven, 2016).

\section{Conclusions and outlook}

Moisture barriers are used as functional interfaces between food products and their environment to limit moisture exchange. In this study, the drying kinetics of composite fruit-barrier systems were quantified by modelling, providing also very local insight on the internal moisture content and water activity distribution.

We identified the impact of the barrier properties, both moisture permeability and thickness, on the dehydration process. The presence of a barrier induced a lower evaporation rate thus a higher tissue temperature, making the fruit more susceptible to damage of its heat-sensitive compounds. The composite nature of the coated fruit tissue makes that the main water activity gradients appear over the barrier, leading to a more homogeneous water activity distribution inside the tissue. The smaller moisture content gradients inside the tissue, and the associated higher water activity at the tissue surface can positively affect fruit quality due to reduced hygric stresses. We also found that the sensitivity of the drying time to the barrier's permeability is dependent on the permeability of the fruit tissue itself. Barrier efficacy is thus strongly connected with the tissue properties.

When quantifying the impact of altering the air speed, thus convective transfer coefficients (CTCs), we showed that the presence of a barrier reduced the sensitivity of the drying time to the CTCs significantly, due to the additional moisture resistance. Nevertheless, a significant reduction of the drying time could be achieved by increasing the CTCs.

In the future, the numerical approach could be applied to determine the optimal barrier permeability and thickness, for a specific application of interest, prior to synthesizing a barrier experimentally. A typical example would be to design a dehydrating film that better retains volatile compounds and that improves texture by avoiding case hardening, but that still has a sufficiently high drying rate to avoid moisture-related spoilage. Other applications outside of food engineering can also be targeted. A typical example would be drying of other composite materials, such as gypsum boards (Defraeye et al., 2012c), where the paper layer forms a barrier to dehydration. In addition to aid in tailoring such barriers to their application, simulations could strongly reduce the need to test these synthesized barriers experimentally on the dehydrated product, as only the barriers permeability and sorption isotherm would need to be measured to "estimate" its effect numerically. 
A particular future model development would be splitting up moisture transfer into liquid and vapor transport. Now transport occurred only in the liquid phase and evaporation took place at the air-barrier interface, so a hydrophilic layer was considered. Splitting up moisture transfer would enable simulating hydrophobic barriers as well.

\section{Acknowledgements}

We acknowledge the support of the World Food System Center (WFSC) of ETH Zürich

(www.worldfoodsystem.ethz.ch) and the support of the Swiss National Science Foundation SNSF (project 200021_160047). Pieter Verboven acknowledges European COST Action FA1106 ('QualiFruit').

\section{References}

Aregawi, W., Defraeye, T., Saneinejad, S., Vontobel, P., Lehmann, E., Carmeliet, J., Derome, D., Verboven, P., Nicolai, B., 2013a. Dehydration of apple tissue: Intercomparison of neutron tomography with numerical modelling. Int. J. Heat Mass Transf. 67, 173-182. doi:10.1016/j.ijheatmasstransfer.2013.08.017

Aregawi, W., Defraeye, T., Verboven, P., Herremans, E., Roeck, G., Nicolai, B., 2013b. Modeling of coupled water transport and large deformation during dehydration of apple tissue. Food Bioprocess Technol. 6, 1963-1978. doi:10.1007/s11947-012-0862-1

ASHRAE, 2010. ASHRAE Handbook - Refrigeration: systems and applications (SI edition). Atlanta.

Ateeque, M., Mishra, R.K., Chandramohan, V.P., Talukdar, P., 2014. Numerical modeling of convective drying of food with spatially dependent transfer coefficient in a turbulent flow field. Int. J. Therm. Sci. 78, 145-157. doi:10.1016/j.ijthermalsci.2013.12.003

Ben Mabrouk, S., Benali, E., Oueslati, H., 2012. Experimental study and numerical modelling of drying characteristics of apple slices. Food Bioprod. Process. 90, 719-728. doi:10.1016/j.fbp.2012.02.001

Bonazzi, C., Dumoulin, E., 2011. Quality changes in food materials as influenced by drying processes, in: Tsotsas, E., Mujumdar, A.S. (Eds.), Modern Drying Technology - Product Quality and Formulation. Wiley-VHC Verlag GmbH, Weinheim, Germany, pp. 1-20.

Defraeye, T., 2014. Advanced computational modelling for drying processes - a review. Appl. Energy 131, 323-344.

Defraeye, T., Aregawi, W., Saneinejad, S., Vontobel, P., Lehmann, E., Carmeliet, J., Verboven, P., Derome, D., Nicolai, B., 2012a. Novel application of neutron radiography to forced convective drying of fruit tissue. Food Bioprocess Technol. 6, 3353-3367. doi:10.1007/s11947-012-0999-y

Defraeye, T., Blocken, B., Carmeliet, J., 2012b. Analysis of convective heat and mass transfer coefficients for convective drying of a porous flat plate by conjugate modelling. Int. J. Heat Mass Transf. 55, 112-124. 
doi:10.1016/j.ijheatmasstransfer.2011.08.047

Defraeye, T., Houvenaghel, G., Carmeliet, J., Derome, D., 2012c. Numerical analysis of convective drying of gypsum boards. Int. J. Heat Mass Transf. 55, 2590-2600. doi:10.1016/j.ijheatmasstransfer.2012.01.001

Defraeye, T., Nicolai, B., Mannes, D., Aregawi, W.A., Verboven, P., Derome, D., 2016a. Probing inside fruit slices during convective drying by quantitative neutron imaging. J. Food Eng.

Defraeye, T., Radu, A., Derome, D., 2016b. Recent advances in drying at interfaces of biomaterials. Dry. Technol.

Defraeye, T., Verboven, P., 2016. Convective drying of fruit: role and impact of moisture transport properties in modelling. Submitted.

Dhall, R.K., 2013. Advances in edible coatings for fresh fruits and vegetables: a review. Crit. Rev. Food Sci. Nutr. 53, 435-450. doi:10.1080/10408398.2010.541568

Esfahani, J. a., Majdi, H., Barati, E., 2014. Analytical two-dimensional analysis of the transport phenomena occurring during convective drying: Apple slices. J. Food Eng. 123, 87-93. doi:10.1016/j.jfoodeng.2013.09.019

Kaya, A., Aydin, O., Dincer, I., 2006. Numerical modeling of heat and mass transfer during forced convection drying of rectangular moist objects. Int. J. Heat Mass Transf. 49, 3094-3103.

doi:10.1016/j.ijheatmasstransfer.2006.01.043

Laurienzo, P., Stasio, M. Di, Malinconico, M., Volpe, M.G., 2010. De-hydration of apples by innovative bio-films drying. J. Food Eng. 97, 491-496. doi:10.1016/j.jfoodeng.2009.11.006

Mayor, L., Sereno, A.M., 2004. Modelling shrinkage during convective drying of food materials: a review. J. Food Eng. 61, 373-386. doi:10.1016/S0260-8774(03)00144-4

Mcminn, W.A.M., Magee, T.R.A., 1999. Principles, methods and applications of the convective drying of foodstuffs. Food Bioprod. Process. 77, 175-193.

Pavlath, A.E., Orts, W., 2009. Edible Films and Coatings: Wy, What, and How?, in: Embuscado, M., Huber, C. (Eds.), Edible Films and Coatings for Food Applications. Springer, pp. 1-23.

Petriccione, M., Sanctis, F. De, Pasquariello, M.S., Mastrobuoni, F., Rega, P., Scortichini, M., Mencarelli, F., 2015. The effect of chitosan coating on the quality and nutraceutical traits of sweet cherry during postharvest life. Food Bioprocess Technol. 8, 394-408. doi:10.1007/s11947-014-1411-x

Phinney, R., Rayner, M., Sjöholm, I., Tivana, L., Dejmek, P., 2015. Solar assisted pervaporation (SAP) for preserving and utilizing fruits in developing countries, in: 3rd Southern African Solar Energy Conference.

Romanazzi, G., Feliziani, E., Baños, S.B., Sivakumar, D., 2015. Shelf life extension of fresh fruit and vegetables by chitosan treatment. Crit. Rev. Food Sci. Nutr. 00-00. doi:10.1080/10408398.2014.900474 
Silva, M.A. Da, Bierhalz, A.C.K., Kieckbusch, T.G., 2012. Influence of drying conditions on physical properties of alginate films. Dry. Technol. 30, 72-79. doi:10.1080/07373937.2011.620727

Thakhiew, W., Waisayawan, P., Devahastin, S., 2011. Comparative evaluation of mathematical models for release of antioxidant from chitosan films prepared by different drying methods. Dry. Technol. 29, 1396-1403. doi:10.1080/07373937.2011.588816

Tzempelikos, D.A., Mitrakos, D., Vouros, A.P., Bardakas, A. V., Filios, A.E., Margaris, D.P., 2015. Numerical modeling of heat and mass transfer during convective drying of cylindrical quince slices. J. Food Eng. 156, 10-21. doi:10.1016/j.jfoodeng.2015.01.017

Vargas, M., Pastor, C., Chiralt, A., McClements, D.J., González-Martínez, C., 2008. Recent advances in edible coatings for fresh and minimally processed fruits. Crit. Rev. Food Sci. Nutr. 48, 496-511. doi:10.1080/10408390701537344

Veraverbeke, E.A., Verboven, P., Van Oostveldt, P., Nicolaï, B.M., 2003a. Prediction of moisture loss across the cuticle of apple (Malus sylvestris subsp. mitis (Wallr.)) during storage: Part 2. Model simulations and practical applications. Postharvest Biol. Technol. 30, 89-97. doi:10.1016/S0925-5214(03)00082-6

Veraverbeke, E.A., Verboven, P., Van Oostveldt, P., Nicolaï, B.M., 2003b. Prediction of moisture loss across the cuticle of apple (Malus sylvestris subsp. mitis (Wallr.)) during storage: Part 2. Model simulations and practical applications. Postharvest Biol. Technol. 30, 89-97. doi:10.1016/S0925-5214(03)00082-6

Wong, T.W., Ashikin, W.H.N.S., Law, C.L., 2014. Evaporation and diffusion transport properties and mechanical properties of alginate dried film. Dry. Technol. 32, 117-125. doi:10.1080/07373937.2013.821479 